\title{
Effects of Polycations on Pulmonary Vascular Permeability in Conscious Sheep
}

\author{
Toshihiko Toyofuku, ${ }^{*}$ Sekiya Koyama," Toshio Kobayashi," Shozo Kusama," and Gou Ueda‡ \\ ${ }^{*}$ First Department of Internal Medicine, and ${ }^{\ddagger}$ Department of Environmental Physiology, Sinshu University School of Medicine, \\ Matsumoto, Nagano 390, Japan
}

\begin{abstract}
The role of charged sites on the permeability characteristics of the pulmonary microvascular barrier were investigated using chronically instrumented unanesthetized sheep. In one series of experiments we studied the effects of the cationic amphiphile, dodecyl trimethylamine (DTA; $297 \mathrm{~mol} \mathrm{wt}$ ), and the anionic amphiphile, SDS (288 mol wt), on lung lymph flow rates $(\mathrm{Ql})$, lung lymph to plasma protein ratios $(\mathrm{L} / \mathrm{P})$, pulmonary hemodynamics, and systemic hemodynamics. DTA significantly increased both $Q 1$ and $L / P$, whereas SDS had a more modest and transient effect on these variables. In a second series of experiments the polycations polybrene and poly- $l$-lysine were found to have very similar effects as those of DTA. In another series of experiments we tested the pretreatment inhibition potential of chlorpheniramine (an $\mathrm{H1}$ receptor antagonist), dibutyryl-cyclic AMP (db-cAMP), and the calcium channel antagonists verapamil and nifedipine on polybrene-induced lung injury. We found that only verapamil and db-cAMP significantly attenuated the permeability effects of polybrene. We conclude that both cationic amphiphiles and polycations cause hemodynamic and permeability alterations in the pulmonary circulation of unanesthetized sheep. In addition, the permeability alterations induced by polybrene can be modulated by intracellular calcium and/or cAMP levels.
\end{abstract}

\section{Introduction}

The transvascular passage of macromolecules is generally accepted to be controlled by molecular size, molecular configuration, and the hemodynamic forces operating across the microvessels. However, there are mounting data suggesting that molecular filtration is also influenced by the interaction of charges on the endothelial surface with charged circulating molecules (1-4). Glomerular capillaries appear to clear anionic molecules more slowly than cationic molecules of very similar hydrodynamic radii (1). In contrast, in pulmonary microvessels the transvascular passage of anionic dextran is facili-

Dr. Toyofuku's present address is Department of Medicine, The University of Chicago, 5841 South Maryland Ave., Chicago, IL 60637. Dr. Koyama's present address is Pulmonary and Critical Care Medicine, Department of Internal Medicine, University of Nebraska, 42 Dewey Ave., Omaha, NE 68105.

Address correspondence to Dr. Toshio Kobayashi, First Department of Internal Medicine, Shinshu University School of Medicine, 3-1-1 Asahi, Matsumoto, Nagano 390, Japan.

Received for publication 14 April 1988 and in revised form 13 February 1989.

J. Clin. Invest.

(c) The American Society for Clinical Investigation, Inc.

0021-9738/89/06/2063/07 \$2.00

Volume 83, June 1989, 2063-2069 tated when compared with neutral dextran (2-5). Since electron microscopic examinations have shown a distribution of anionic sites on the endothelial surface in both glomeruli and pulmonary microvessels (5-7), differences in transport of macromolecules based on molecular charge between these organs might be attributed to the charge and construction of the basement membranes and interstitium (4).

How alterations in charged sites on the endothelial surface influence the transport properties of macromolecules is of great interest. To alter the charged sites on cellular surfaces, two methods can be used: infusion of $(a)$ charged amphiphiles or $(b)$ polycations. Charged amphiphiles probably enter the bilipid cell membrane with their hydrophobic portion, thereby exposing their charged hydrophilic tail on the cell surface. Polycations, on the other hand, probably interact with the anionic sites (i.e., neutralize) on the cell surface.

The first purpose of this investigation was to determine the effects of altered pulmonary microvascular charge on protein transport using two amphiphiles (with identical hydrophobic alkyl chains but opposite hydrophilic charged groups) and polycations. We and others (8-12) have observed that infusions of cationic amphiphiles and polycations increase plasma protein clearance. Although an increase in protein transport indicates the possibility that cationic amphiphiles and polycations neutralize endothelial charged sites, it is unclear whether physical cellular alterations occur (i.e., increased intercellular gap junction size), thereby increasing macromolecular transport.

The second purpose was to examine whether polybrene, a polycation, increases macromolecular transport by a mechanism dependent on intracellular cAMP and/or calcium levels, which have been suggested to control intercellular gap junctions (13-15). To test this possibility, we pretreated sheep with two calcium channel antagonists, nifedipine and verapamil, and dibutyryl-cyclic AMP (db-cAMP) ${ }^{1}$ before polybrene-induced lung injury.

\section{Methods}

\section{Experimental protocols}

GENERAL PROTOCOL

Five series of experiments were conducted on chronically instrumented unanesthetized sheep. In the first two series we evaluated the effects of the amphiphiles dodecyl trimethylamine (DTA) and SDS, and polycations polybrene and poly- $l$-lysine, on pulmonary microvascular permeability. In the other three series we tested the potential attenuation of polybrene-induced increased microvascular permeabil-

1. Abbreviations used in this paper: $\mathrm{Cl}$, lung lymph protein clearance; CO, cardiac output; db-cAMP, dibutyryl-cAMP; DTA, dodecyl trimethylamine; L/P, lung lymph to plasma protein ratio; Ppa, pulmonary arterial pressure; Psa, aortic pressure; Pw, pulmonary arterial wedge pressure; Q1, lung lymph flow. 
ity alterations with $(a)$ chlorpheniramine, an $\mathrm{H} 1$ receptor antagonist, (b) db-cAMP, and (c) two calcium channel antagonists, verapamil and nifedipine. Pulmonary microvascular permeability was assessed by the method suggested by Taylor et al. (16) which uses the relationship of lymph flow rate to the lymph to plasma protein concentration ratio. Each sheep was allowed to recover from surgical procedures for a minimum of $7 \mathrm{~d}$ before being subjected to experimental protocols. After a 2-h baseline period one of the inhibitors or its vehicle was infused intravenously. $45 \mathrm{~min}$ after the start of the pretreatment infusion we infused one of the amphiphiles or polycations over $30 \mathrm{~min}$. During the next $4 \mathrm{~h}$ aortic (Psa), pulmonary arterial (Ppa), and pulmonary arterial wedge ( $\mathrm{Pw}$ ) pressures, cardiac output (CO), and lung lymph flow rate $(\mathrm{Ql})$ were measured every $15 \mathrm{~min}$ while blood and lung lymph samples were taken every $30 \mathrm{~min}$ for total protein and albumin concentration measurements. TXB2, 6-keto-PGF ${ }_{1 \alpha}$, peripheral leukocyte, and platelet measurements were determined at baseline, $0.5,1,2$, 3 , and $4 \mathrm{~h}$ after beginning the infusion of amphiphiles or polycations.

\section{SPECIFIC PROTOCOLS}

Series 1: Effects of amphiphiles (six sheep). To compare the effects of two differently charged amphiphiles on the transport properties of the pulmonary microvasculature for plasma proteins, we intravenously infused vehicle $(30 \mathrm{ml}$ normal saline), vehicle with DTA $\left(\mathrm{CH}_{3}\left(\mathrm{CH}_{2}\right)_{11} \mathrm{~N}^{+}\left(\mathrm{CH}_{3}\right)_{3} \mathrm{Br}^{-}\right.$; Sigma Chemical Co., St. Louis, MO), or vehicle with SDS $\left(\mathrm{CH}_{3}\left(\mathrm{CH}_{2}\right)_{11} \mathrm{OSO}_{3} \mathrm{Na}\right.$; Sigma Chemical Co.). SDS and DTA were chosen for their similar molecular weights yet opposite hydrophilic charges, and because their effect on isolated rat lung water accumulation has been previously reported (10). In three sheep DTA or SDS were infused at three rates $(20,100$, and $500 \mu \mathrm{g} / \mathrm{kg}$ over $30 \mathrm{~min})$ to determine if lung lymph increases in a dose-dependent manner. In the other three sheep SDS or DTA infusions were repeated at a dose of $100 \mu \mathrm{g} / \mathrm{kg} \mathrm{2-3}$ times over a period of 7-14 $\mathrm{d}$ to test the reproducibility of the responses. In total, 10 infusions at $100 \mu \mathrm{g} / \mathrm{kg}$ were done for SDS or DTA in these six sheep.

Series 2: Effects of polycations (six sheep). To ascertain the effects of polycations on the permeability characteristics of the pulmonary circulation, we infused vehicle or vehicle with poly-l-lysine $\left(\left[\mathrm{NH}\left[\mathrm{CH}\left(\mathrm{CH}_{2}\right)_{4} \mathrm{~N}^{+} \mathrm{H}_{3} \mathrm{Br}^{-}\right] \mathrm{CO}\right]_{12} ;\right.$ Sigma Chemical Co.) at $100 \mu \mathrm{g} / \mathrm{kg}$, or vehicle with polybrene $\left(\left[\left[\mathrm{N}^{+}\left(\mathrm{CH}_{3}\right)_{2}\left(\mathrm{CH}_{2}\right)_{6} \mathrm{~N}^{+}\left(\mathrm{CH}_{3}\right)_{2}\left(\mathrm{CH}_{2}\right)_{3}\right]\right.\right.$ $\left.2 \mathrm{Br}^{-}\right]_{12}$; Sigma Chemical Co.) at $100 \mu \mathrm{g} / \mathrm{kg}$. These polycations were chosen due to previous reports on their effects on the pulmonary circulation $(9,11,12)$.

Series 3: Effects of chlorpheniramine on the pulmonary responses to polybrene (six sheep). To determine if the apparent increase in pulmonary microvascular permeability by polybrene was mediated by histamine, we injected chlorpheniramine, an $\mathrm{H} 1$-histamine receptor antagonist ( $2 \mathrm{mg} / \mathrm{kg}$; Sankyo Pharmaceutical Co., Tokyo, Japan), over 5 $\mathrm{min}, \mathbf{4 5} \mathrm{min}$ before the polybrene infusion. This dose of chlorpheniramine has been reported to totally block the pulmonary vascular pressure response to histamine in sheep (17).

Series 4: Effects of calcium channel antagonists on the pulmonary responses to polybrene (six sheep). Since transmembrane calcium influx may mediate polybrene-induced lung injury, we infused verapamil ( $20 \mu \mathrm{g} / \mathrm{kg}$ per min; Eizai Pharmaceutical Co., Tokyo, Japan) 45 min before polybrene infusion. Verapamil has been found to be effective in the prevention of microvascular damage in other animal models (18-20). To determine if the effects of verapamil were due to inhibition of transmembrane calcium flux, we also used nifedipine $(4 \mu \mathrm{g} / \mathrm{kg}$ per min; Bayer-Takeda Pharmaceutical Co., Tokyo, Japan), a structurally different compound that is thought to have a different site of action from verapamil $(21,22)$.

Series 5: Effects of $d b$-cAMP on the pulmonary responses to polybrene (six sheep). Db-cAMP passes through cell membranes and is converted to cAMP, $N$-monobutyryl adenosine 3,5-cyclic monophosphate, and 2-o-monobutyryl adenosine 3,5-cyclic monophosphate by deacylation (23). Since we have recently reported that db-cAMP attenuated the responses of sheep to endotoxemia (24), we tested the possibility that increased intracellular cAMP levels may also protect against polybrene-induced lung damage. We began an infusion of $\mathrm{db}$ cAMP (Dai-ichi Pharmaceutical Co., Tokyo, Japan) at $40 \mu \mathrm{g} / \mathrm{kg}$ per min $45 \mathrm{~min}$ before polybrene infusion and continued the db-cAMP infusion until the conclusion of the experiment.

\section{Experimental preparations}

Adult sheep weighing $20-30 \mathrm{~kg}(n=6)$ were initially anesthetized with an infusion of sodium pentobarbital, $12.5 \mathrm{mg} / \mathrm{kg}$ i.v. The sheep were then intubated and ventilated at $15 \mathrm{ml} / \mathrm{kg}$ tidal volume at a rate of 10-14 breaths/minute with a respirator (Harvard Apparatus Co., Inc., S. Natick, MA). Anesthesia was maintained with $1 \%$ halothane in $20 \%$ $\mathrm{O}_{2}$ and the balance $\mathrm{N}_{2}$. The caudal mediastinal lymph node was located through a right thoracotomy, the efferent duct of the node cannulated with a thin silicone tube, and the node ligated and cut caudally to the inferior pulmonary ligament. Diaphragmatic lymphatics were interrupted on both the right and left sides to further minimize contamination by nonpulmonary lymph (25). In addition, we placed polyvinyl catheters in the aorta and superior vena cava, and a Swan-Ganz thermodilution catheter in the pulmonary artery.

\section{Measurements}

All measurements were made with the animals awake and standing. Psa, Ppa, and Pw were measured using calibrated pressure transducers (Statham P50) attached to a point on the shoulder considered to be at the level of the left atrium, and recorded on an eight-channel recorder (WT 685; Nihon Koden Co., Tokyo, Japan). CO was measured by thermodilution using a CO computer (model 9520; Edwards Laboratories, Santa Ana, CA). Circulating blood leukocytes and platelets were counted with a microcell counter (CC-100; Toa Co., Kobe, Japan) and a platelet counter (PL-100; Toa Co.), respectively.

\section{Prostaglandin analysis}

TXB2 and 6-keto-PGF ${ }_{1 \alpha}$ concentrations (stable metabolites of TXA2 and prostacyclin, respectively) were measured by RIA in plasma and lung lymph (26).

\section{Statistics}

Data are presented as mean \pm SEM. Changes in measured variables over time and between groups were analyzed by two-way analysis of variance, and differences were tested by Duncan's multiple range test. Significant differences for all comparisons were accepted for $P<0.05$.

\section{Results}

Shortly after infusion of DTA, SDS, polybrene, or poly-l-lysine $\mathrm{Ppa}, \mathrm{Pw}$, and Q1 increased, L/P decreased, and CO and Psa were not significantly altered. The responses to SDS were transient and returned to near baseline $2 \mathrm{~h}$ after SDS infusion (Fig. 1). However, the responses to DTA (Fig. 1) and the polycations (Fig. 2) were more sustained and L/P actually increased above baseline values at $2.5-4 \mathrm{~h}$.

Fig. 3 depicts the $L / P$ response (averaged values $2-4 \mathrm{~h}$ after infusion) normalized to its baseline value as a function of $\mathrm{Q}$ normalized to its baseline value. Theoretically, increased microvascular permeability should cause a greater transport of protein for a given increase in Ql compared with normal microvessels. Our results are compared with data obtained during increased microvascular pressure (27). DTA, polybrene, and poly-l-lysine, but not SDS, data suggest an increase in pulmonary microvascular permeability as evidenced by high $L / P$ values at elevated lymph flow rates compared with elevated pressure data.

Lung lymph protein clearances $(\mathrm{Cl})$ were calculated for albumin and the remaining plasma proteins (i.e., total plasma proteins minus albumin) by multiplying the lymph to plasma 

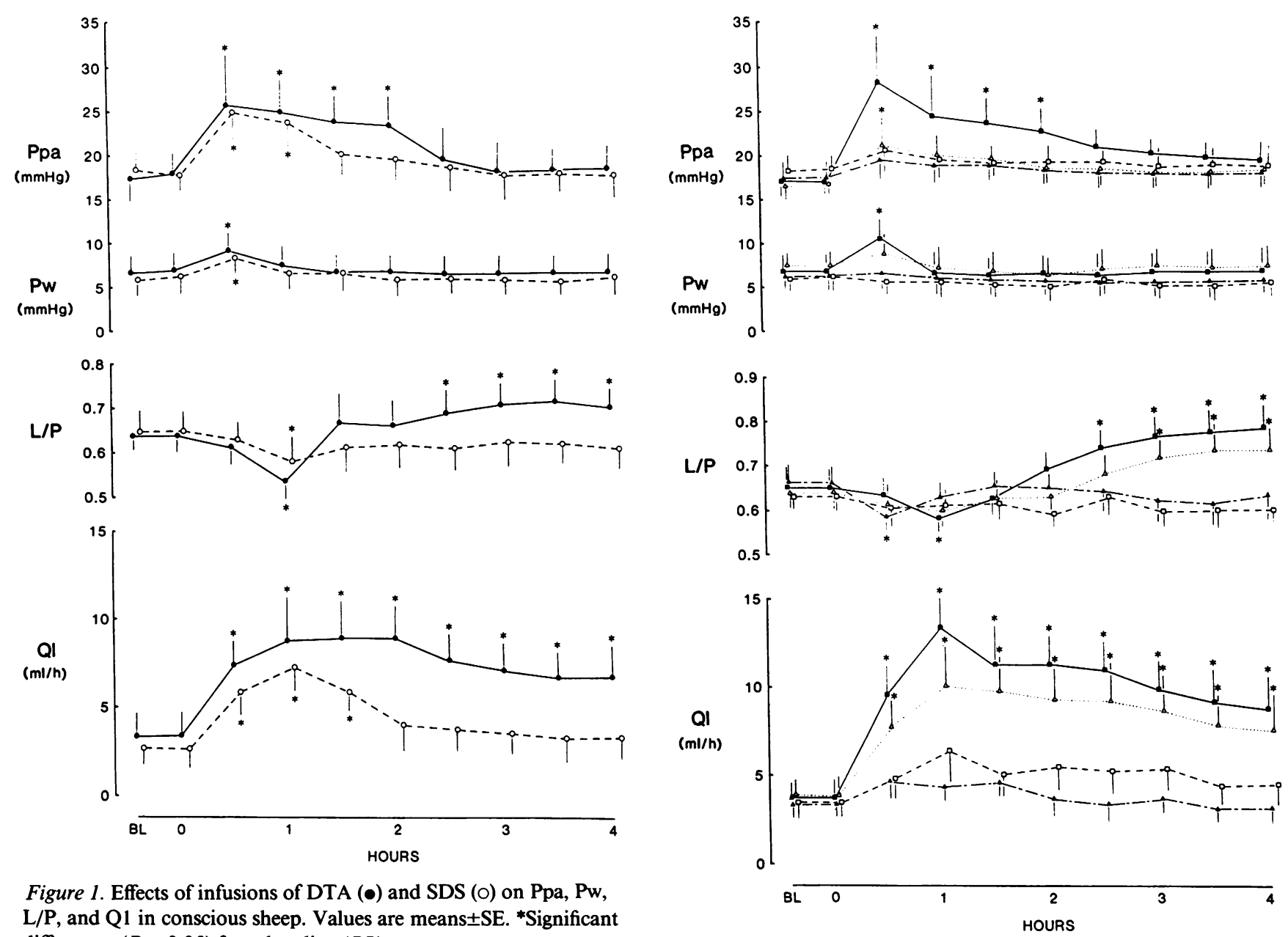

$\mathrm{L} / \mathrm{P}$, and $\mathrm{Q} 1$ in conscious sheep. Values are means $\pm \mathrm{SE}$. *Significant differences $(P<0.05)$ from baseline $(B L)$.

protein ratios by the lymph flow rate. Fig. 4 shows clearance rates at selected time points for both albumin and other proteins normalized to their baseline values. Both albumin and other proteins had similar $\mathrm{Cl}$ responses for each of the four challenge substances.

After the infusion of amphiphiles or polycations, circulating peripheral leukocyte counts rapidly decreased and then slowly returned toward normal values as illustrated by Fig. 5 . Interestingly, circulating platelet counts were virtually unaffected by amphiphiles or polycations.

TXB2 levels were not altered in either plasma or lung lymph for any of the challenge substances studied. However, 6-keto-PGF ${ }_{1 \alpha}$ levels (Fig. 6) were increased soon after challenge and slowly decreased to baseline values with the greater increases occurring in lung lymph. Although SDS did cause a statistical increase in lymph 6-keto- $\mathrm{PGF}_{1 \alpha}$ levels, the increase was small compared with the effect obtained after DTA infusion.

Pretreatment with chlorpheniramine had no discernable effect on any of the measured variables after polybrene challenge. However, db-cAMP pretreatment prevented significant alterations in any of the measured variables except for the leukopenia. Interestingly, verapamil, but not nifedipine, pretreatment significantly attenuated the increases in Ppa, Pw, Q1, and the later increases in L/P. Neither verapamil nor nifedipine had any effect on leukopenia or increases in blood or lymph 6-keto-PGF ${ }_{1 \alpha}$.

Figure 2. Effects of polybrene on $\mathrm{Ppa}, \mathrm{Pw}, \mathrm{L} / \mathrm{P}$, and $\mathrm{Q} 1$ in conscious sheep pretreated with vehicle $(\square)$, db-cAMP ( $\square)$, verapamil $(\Delta)$, and nifedipine $(\Delta)$. Values are means \pm SE. ${ }^{*}$ Significant differences $(P$ $<0.05)$ from baseline $(B L)$.

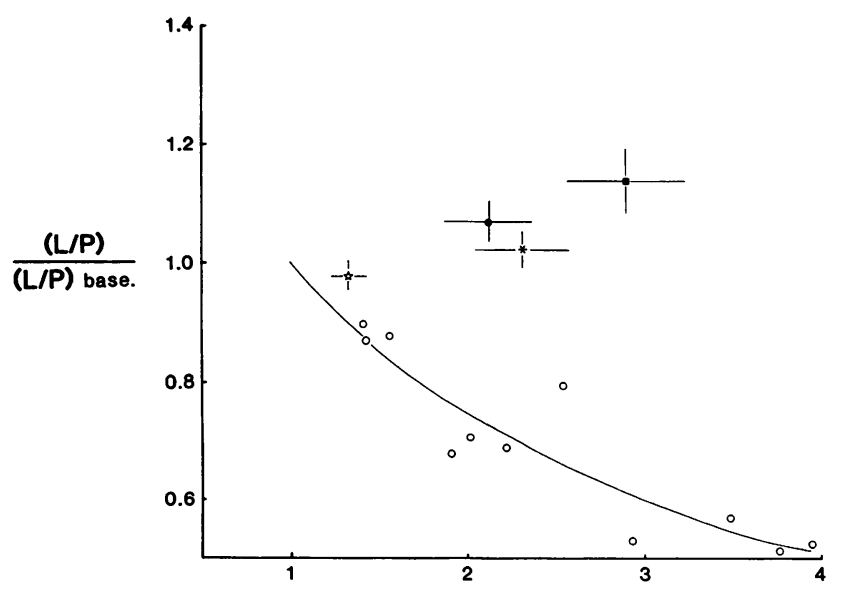

(QI) / (QI) base.

Figure 3. L/P normalized to baseline as a function of $\mathrm{Q} 1$ normalized to baseline. $\bigcirc$, Elevated plasma (cumulative data from Parker et al. [27] using conscious sheep); •, DTA; $₫$, polybrene; *, poly-l-lysine; and $\star$, SDS (means \pm SE in the present study). 

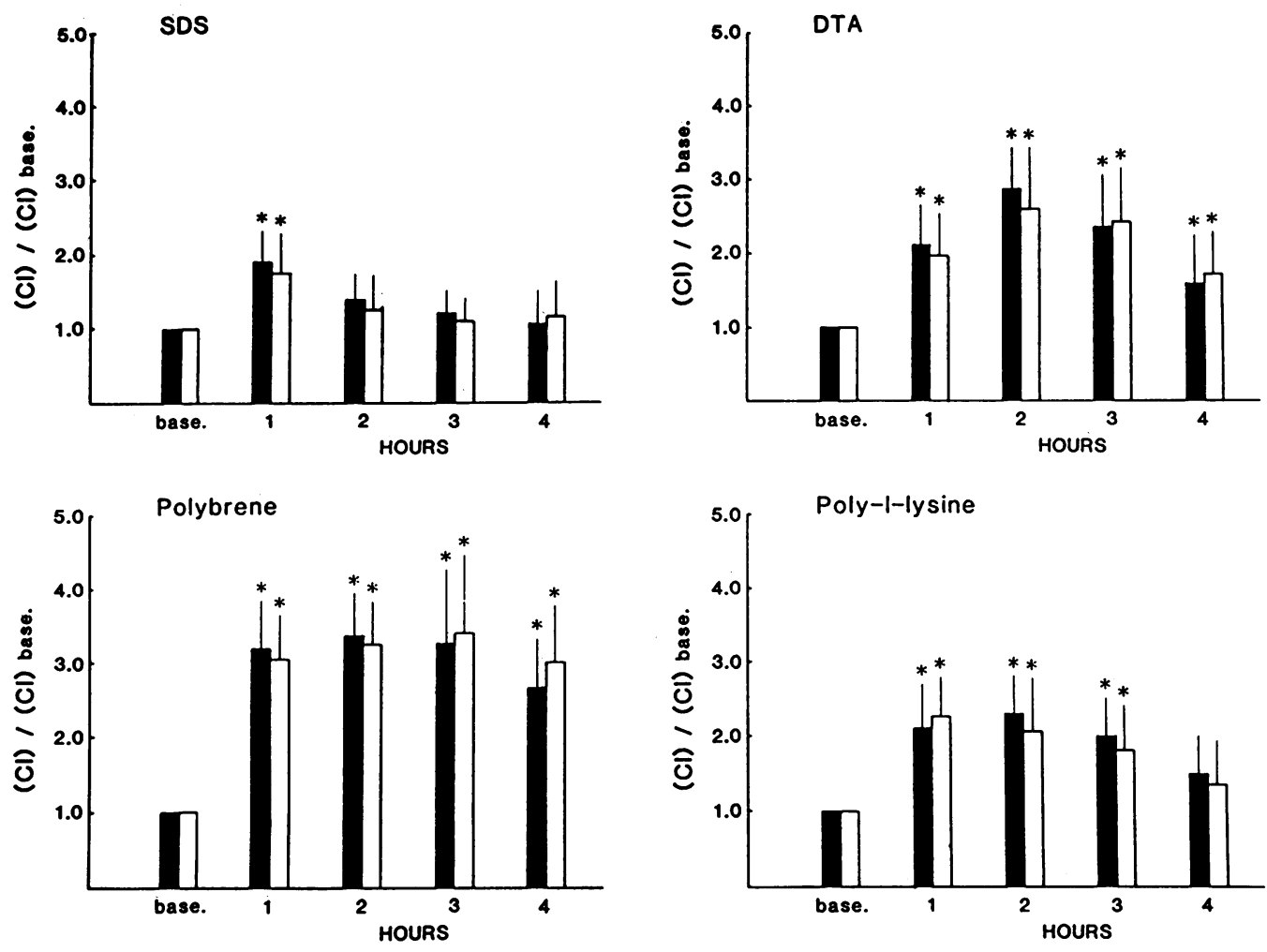

Figure 4. A comparison of $\mathrm{Cl}$ of albumin (solid bars) and other proteins (open bars) normalized to the respective baselines after infusions of SDS, DTA, polybrene, and poly-l-lysine. Values are means \pm SE. *Significant differences $(P<0.05)$ from baseline.

\section{Discussion}

The effects of polycations on the lung have been the subject of several investigations (9-12). In this investigation intravenous infusions of two polycations caused a significant increase in protein-rich lung lymph, indicating an increase in pulmonary vascular permeability. The cationic amphiphile, DTA, but not the anionic one, SDS, caused a similar apparent increase in pulmonary vascular permeability despite the fact that the interaction of DTA with the plasma-lymph barrier per se is probably different than that of polycations. Our results suggest that the cationic property of these molecules has a crucial role in increasing pulmonary vascular permeability. However, Morel et al. (28) have demonstrated that pulmonary vascular responses to protamine sulfate in sheep are different from those to polybrene, poly-l-lysine, and DTA. This would indicate that the effects of polycations can be influenced by their respective chemical properties, as well as their common cationic one.

Assuming that pulmonary vascular permeability is indeed increased by polycations, the precise mechanism(s) by which they increase permeability is unclear. At least three mechanisms could theoretically explain our data as described below.

1. Polycation-induced mediator release. Since the polycation infusions caused leukopenia (Fig. 5), it is possible that leukocyte activation also occurred. Activated leukocytes are thought to cause permeability alterations by a number of mediators (e.g., toxic oxygen radicals and proteases). However, circulating leukocyte activation per se does not appear to be the main cause of the polycation-induced permeability alterations for three reasons. First, the polyanion SDS caused a similar leukopenia without an apparent increase in permeability. Second, leukopenia was not affected by db-cAMP or verapamil despite the fact that both appeared to greatly attenuate polycation-induced permeability alterations. Third, polycat- ions have been shown to increase pulmonary permeability in isolated rat lungs perfused with blood-free Ringer's solution $(10-12)$. However, it should be pointed out that leukopenia may not be an accurate indicator of leukocyte activation (29). In addition, verapamil and db-cAMP may have exerted their protective effects by blocking leukocyte activation after chemotaxis had occurred.

Polycations have been shown to cause histamine release (30), which may have caused an increase in permeability. However, Rippe et al. (31) have reported that histamine does not increase permeability. Moreover, pretreatment with the antihistamine, chlorpheniramine, did not attenuate the permeability alterations in our experiments.

2. Polycation-induced polyanion charge or shape alterations. Another possible mechanism by which polycations could have altered protein transport is by altering either the shape or net charge of the proteins. This does not appear to be a viable mechanism due to the fact no such effect has been shown for albumin exposed to protamine (32).

3. Polycation interaction with anionic sites on the plasmalymph barrier. The plasma-lymph barrier is generally considered to consist of several components (i.e., endothelial cells, basement membrane, interstitial matrix, and the lymphatic endothelial cells). Negatively charged carboxyl and sulfate groups abound on the glycocalyx of endothelial and interstitial cellular surfaces, in the intercellular junctions, basement membrane, and on the proteoglycans and glycosaminoglycans of the interstitial matrix $(6,7)$. Previous studies have indicated that anionic macromolecules are more rapidly transported across lung microvessels than cationic macromolecules of comparable size. Several investigators have demonstrated that pulmonary vascular macromolecular transport is increased after intravenous infusions of the polycations, protamine sulfate, polybrene, and poly-l-lysine (10-12), and that heparin 
A

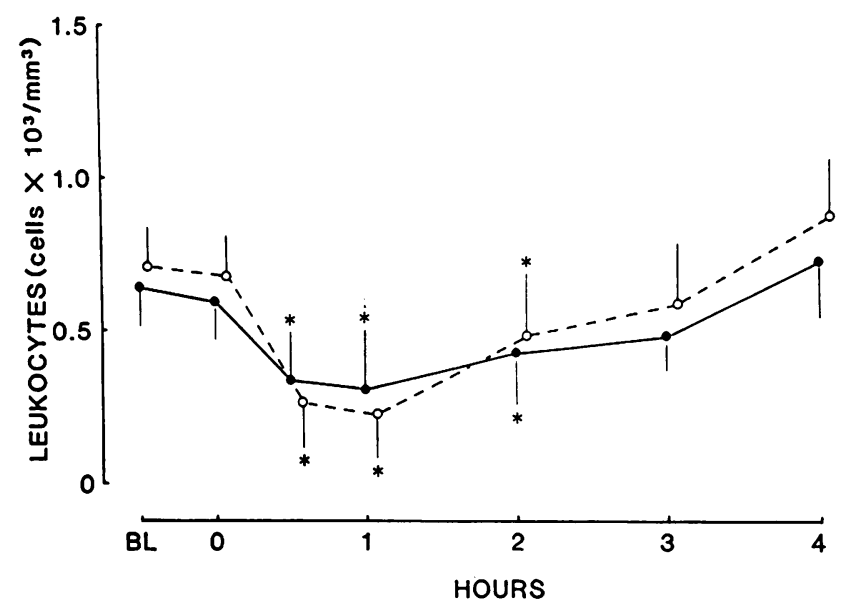

B

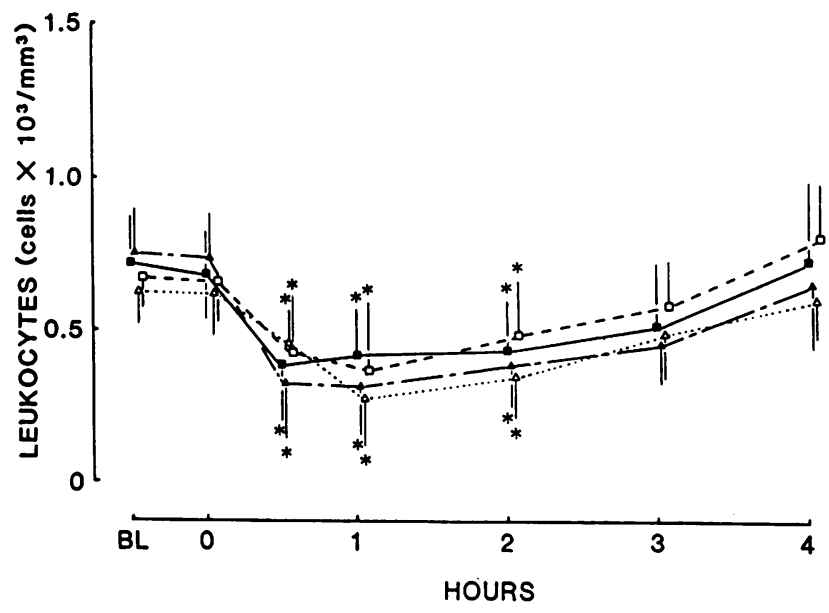

Figure 5. (A) Effects of infusions of DTA (•) and SDS (0) on peripheral leukocytes in conscious sheep. $(B)$ Effects of infusions of polybrene on peripheral leukocytes in conscious sheep pretreated with vehicle ( () , db-cAMP $(\square)$, Verapamil $(\Delta)$, and nifedipine $(\Delta)$. Values are means \pm SE. *Significant differences $(P<0.05)$ from baseline $(B L)$.

sulfate, an anionic glycoprotein, prevented this increase in macromolecular transport $(11,12)$. Moreover, Skutelsky et al. (8) have demonstrated that positively charged ferritin interacts with negatively charged sites on endothelial cells, which, after internalization of the ferritin, left most of the luminal surface devoid of negatively charged sites. These data would suggest that polycations do alter the plasma-lymph transport properties of proteins via interaction with anionic sites on the plasma-lymph barrier.

The anionic sites of the plasma-lymph barrier could influence charged macromolecular transport by at least two mechanisms: (a) the microvascular membrane could behave as an effective charged barrier and/or $(b)$ the anionic sites at the endothelial cellular membrane, basement membrane, and interstitial matrix could interact with cationic macromolecules to retard their passage from the plasma to the lymphatics (i.e., a cation-exchange gel). Parker et al. (4) have reported data that suggest the plasma-lymph barrier of the pulmonary circulation does behave as a cationic-exchange structure. Their data indi- cated that cationic molecules have greater initial clearance values and larger extravascular volumes than anionic molecules of similar size in normal lungs. According to Parker's concept, infused polycations are reversibly bound to anionic sites of the plasma-lymph barrier, which would appear to behave as a net cationic barrier if short-term mass transfer of a polycation from the plasma to collected lung lymph is used as an indicator of permeability. However, in our study polycation infusions increased the clearance of albumin and other plasma proteins to similar degrees, despite the fact that albumin is more anionic than other plasma proteins (Fig. 4). We therefore conclude that the polycations used in this investigation increase plasma-lymph transport of plasma proteins by an apparent structural rearrangement of some part(s) of the plasma-lymph barrier in addition to neutralization of the anionic sites of the barrier.

The precise mechanism of macromolecular transport across the plasma-lymph barrier is controversial. One proposed mechanism is endothelial contraction, which results in opening of leaky sites and thus increased protein permeability $(33-35)$. It has been reported that endothelial contraction is mediated by transformation of intracellular microfilaments, the magnitude of which may be dependent on intracellular cAMP and/or calcium levels (13-15). Polycations have also been reported to change the membrane permeability to ions, resulting in electrochemical alterations (36). Mayhan and Joyner (18) have demonstrated that external calcium modulates microvascular leaky sites in the hamster pouch. To test whether this mechanism may play a role in the polycation-induced permeability alterations, we pretreated sheep with dbcAMP and the calcium channel antagonists nifedipine and verapamil before polybrene infusion. Both db-cAMP and verapamil were found to greatly attenuate the permeability alterations, whereas nifedipine had little effect at the dosage used. The different effects of verapamil and nifedipine on polybrene-induced permeability alterations may be due to the dosages used and/or the site of action of the two calcium channel antagonists may not be the same $(2 i, 22)$. Another possibility is that db-cAMP and verapamil have similar actions on intracellular cAMP levels, as Della Bianca et al. (37) have recently reported that verapamil causes an increase in intracellular cAMP levels. Several investigators $(38,39)$ have also reported an attenuation of permeability alterations with neophylline, theophylline, and $\mathrm{PGE}_{1}$, all of which increase intracellular cAMP levels.

The mechanism by which cAMP attenuated permeability alterations by polybrene is unclear. One potential mechanism is that cAMP mediates endothelial contraction by directly regulating intracellular myosin light chain kinase in a manner similar to smooth muscle cells (40). An alternative mechanism is that cAMP regulates localized intracellular calcium release in a reciprocal manner, as has been shown in smooth muscle cells (20) and platelets (41).

Polybrene, poly-l-lysine, DTA, and SDS induced prostacyclin production, but not TX production in this investigation. Prostacyclin has been shown to be produced mainly by endothelial cells and partially by the subendothelium (42), and has been suggested to be an early marker of endothelial damage (43). The increase of 6-keto-PGF ${ }_{1 \alpha}$ concentration was greater in lung lymph than plasma, suggesting that a majority of its production was by the lung (44). Prostacyclin production was found to be much greater after DTA infusion than SDS infu- 
A
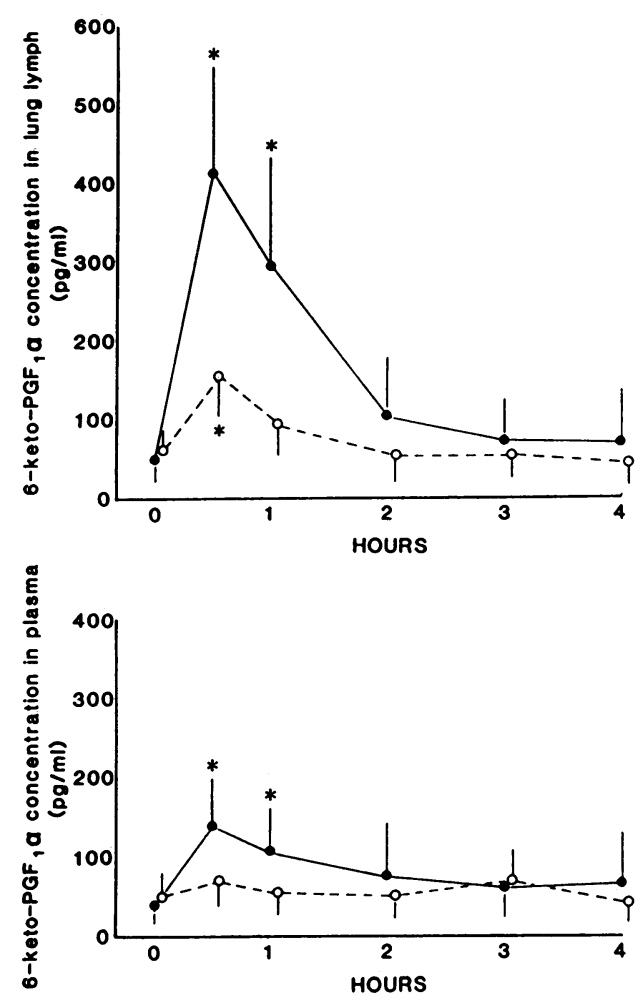

sion, which would suggest that DTA caused more damage to endothelial cells than SDS. However, both verapamil and dbcAMP appear to effectively attenuate permeability alterations by polybrene, yet verapamil did not block prostacyclin production. This would suggest either that $6-$ keto-PGF $_{1 \alpha}$ is not a reliable indicator of endothelial damage or that verapamil has a different mode of action from that of db-cAMP. Although the induction of prostacyclin production by calcium ionophore A23187 may be mediated by an increase in intracellular calcium by extracellular calcium, this has not been found for thrombin, bradykinin, and histamine (45).

In conclusion, our data indicate that the polycations used in this investigation and DTA cause an increase in pulmonary microvascular permeability. Whether the mechanisms by which DTA and polybrene induce permeability alterations are similar remains to be determined. Polybrene-induced permeability alterations can be greatly attenuated by either verapamil or db-cAMP.

\section{Acknowledgements}

We would like to thank Richard E. Parker and Alexandre Stewart for their critical reading of the manuscript and Kumiko Fukumitsu for her technical assistance in the measurement of prostanoids.

\section{References}

1. Brenner, B. M., T. H. Hostetter, and H. D. Humes. 1978. Glomerular permeability: barrier function based on discrimination of molecular size and charge. Am. J. Physiol. 235:F455-F460.

2. Glauser, F. L., R. P. Fairman, and J. E. Millen. 1982. Facilitated transport of anionic dextrans in the pulmonary microvasculature of normal sheep. Microcirculation. 2:305-313.
B

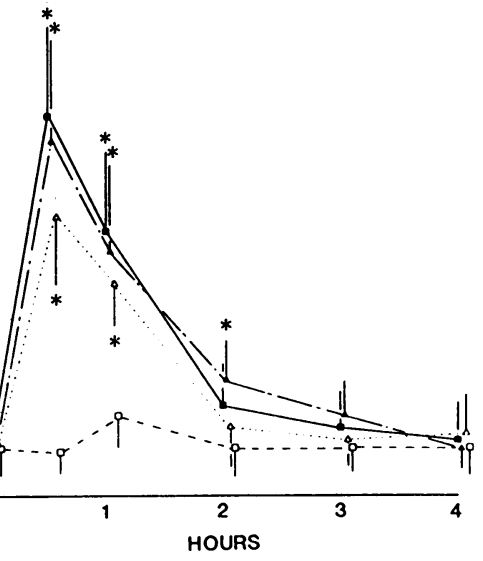

Figure 6. (A) Effects of infusions of DTA $(\bullet)$ and SDS (O) on concentrations of 6keto-PGF $F_{1 \alpha}$ in conscious sheep. $(B)$ Effects of infusions of polybrene on concentrations of 6-keto-PGF ${ }_{1 \alpha}$ in conscious sheep pretreated with vehicle (a), db-cAMP $(\square)$, verapamil (४), and nifedipine $(\Delta)$. Values are means \pm SE. *Significant differences $(P<0.05)$ from baseline.
3. Lanken, P. N., J. H. Hansen-Flaschen, P. M. Sampson, G. G. Pietra, F. R. Haselton, and A. P. Fishman. 1985. Passage of uncharged dextrans from blood to lung lymph in awake sheep. J. Appl. Physiol. 59:580-591.

4. Parker, J. C., S. Gilchrist, and J. T. Cartledge. 1985. Plasmalymph exchange and interstitial distribution volumes of charged macromolecules in the lung. J. Appl. Physiol. 59:1128-1136.

5. Pietra, G. G., A. P. Fishman, P. N. Lanken, P. Sampson, and J. Hansen-Flaschen. 1982. Permeability of pulmonary endothelium to neutral and charged macromolecules. Ann. NY Acad. Sci. 384:381393.

6. Simionescu, M., N. Simionescu, J. E. Silbert, and G. E. Palade. 1981. Differentiated microdomains on the luminal surface of the capillary endothelium. II. Partial characterization of their anionic sites. $J$. Cell Biol. 90:614-621.

7. Brody, J. S., C. A. Vaccaro, N. S. Hill, and S. Rounds. 1984. Binding of charged ferritin to alveolar wall components and charge selectivity of macromolecular transport in permeability pulmonary edema in rats. Circ. Res. 55:155-167.

8. Skutelsky, E., and D. Danon. 1976. Redistribution of surface anionic sites on the luminal front of blood vessel endothelium after interaction with polycationic ligand. J. Cell Biol. 71:232-241.

9. Vehasskari, V. M., C. T. C. Chang, J. K. Stevens, and A. M. Robson. 1984. The effects of polycations on vascular permeability in the rat. A proposed role for charged sites. J. Clin. Invest. 73:10531061.

10. Sunnergren, K. P., and R. P. Fairman. 1986. Charged amphiphiles alter alveolar capillary membrane permeability. Am. Rev. Respir. Dis. 317:A267. (Abstr.)

11. Fairman, R. P., C. N. Sessler, M. Bierman, and F. L. Glauser. 1987. Protamine sulfate causes pulmonary hypertension and edema in isolated rat lungs. J. Appl. Physiol. 62:1363-1367.

12. Chang, S., J. Y. Westcott, J. E. Henson, and N. F. Voelkel. 1987. Pulmonary vascular injury by polycations in perfused rat lungs. J. Appl. Physiol. 62:1932-1943.

13. Martinez-Palomo, A., I. Meza, G. Beaty, and M. Cereijido. 
1980. Experimental modulation of occluding junctions in a cultured transporting epithelium. J. Cell Biol. 87:736-745.

14. Duffey, M. E., B. Hainau, S. Ho, and C. J. Bentzel. 1981. Regulation of epithelial tight junction permeability by cyclic AMP. Nature (Lond.). 294:451-453.

15. Palant, C. E., M. E. Duffey, B. K. Mookertjee, S. Ho, and C. J. Bentzel. 1983. Ca regulation of tight-junction permeability and structure in Necturus gallbladder. Am. J. Physiol. 245(Cell Physiol. 14):C203-C212.

16. Taylor, A. E., J. C. Parker, D. N. Granger, N. A. Mortillaro, and G. Rutili. 1981. Assessment of capillary permeability using lymphatic protein flux: estimation of the osmotic reflection coefficient. In Microcirculation: Current Physiological Medical and Surgical Concepts. R. E. Effros, H. Schmid-Schonbein, and J. Ditzel, editors. Academic Press, New York. 19-32.

17. Ahmed, T., W. Oliver, Jr. B. L. Frank, M. J. Robinson, and A. Wanner. 1982. Hypoxic pulmonary vasoconstriction in conscious sheep: role of mast cell degranulation. Am. Rev. Respir. Dis. 126:291297.

18. Mayhan, W. G., and W. L. Joyner. 1984. The effect of altering the external calcium concentration and a calcium channel blocker, verapamil, on microvascular leaky sites and dextran clearance in the hamster cheek pouch. Microvasc. Res. 28:159-179.

19. Allison, R. C., K. T. Marble, E. M. Hernandez, M. I. Townsley, and A. E. Taylor. 1986. Attenuation of permeability lung injury after phorbol myristate acetate by verapamil and OKY-046. Am. Rev. Respir. Dis. 134:93-100.

20. Richards, I. S., J. Ousterhout, N. Sperelakis, and C. G. Murlas. 1987. Cyclic AMP suppresses calcium-dependent electrical activity of airway smooth muscle induced by TEA. J. Appl. Physiol. 62:175-179.

21. Church, J., and T. T. Zoster. 1980. Calcium antagonistic drugs: mechanisms of action. Can. J. Physiol. Pharmacol. 58:254-264.

22. Mehta, J. L. 1985. Influence of calcium-channel blockers on platelet function and arachidonic acid metabolism. Am. J. Cardiol. 55:158B-164B.

23. Falbriad, J. G., T. Posternak, and E. W. Sutherland. 1967. Preparation of derivatives of adenosine 3', 5'-phosphate. Biochim. Biophys. Acta. 148:99-105.

24. Koyama, S., T. Kobayashi, T. Toyofuku, M. Fukushima, and S. Kusama. 1987. Intracellular augmentation of cyclic AMP attenuates lung injury inducted by endotoxin in conscious sheep. Am. Rev. Respir. Dis. 135:A82. (Abstr.)

25. Roos, P. J., J. P. Wiener-Kronish, K. H. Albertine, and N. C. Staub. 1983. Removal of abdominal sources of caudal mediastinal node lymph in anesthetized sheep. J. Appl. Physiol. 55:996-1001.

26. Toyofuku, T., K. Kubo, T. Kobayashi, and S. Kusama. 1986. Effects of ONO-6240, a platelet-activating factor antagonist, on endotoxin shock in unanesthetized sheep. Prostaglandins. 31:271-281.

27. Parker, R. E., R. J. Roselli, T. R. Harris, and K. L. Brigham. 1981. Effects of graded increases in pulmonary vascular pressures on lung fluid balance in unanesthetized sheep. Circ. Res. 49:1164-1172.

28. Morel, D. R., T. Nguyerduy, G. Collee, T. Wonders, C. Melvin, D. Robinson, E. Lowenstein, J. E. Repine, and W. M. Zapol. 1985 Thromboxane mediates acute pulmonary vasoconstriction during heparin reversal by protamine in sheep. Fed. Proc. 44:625. (Abstr.)

29. Meyrick, B., L. H. Hoffman, and K. L. Brigham. 1984. Chemotaxis of granulocytes across bovine pulmonary artery intimal explants without endothelial cell injury. Tissue \& Cell. 16:1-16.
30. Douglas, W. W. 1980. Histamine and 5-hydroxytryptamine (serotonin) and their antagonists. In The Pharmacological Basis of Therapeutics. A. G. Gilman, L. S. Goodman, and A. Gilman, editors. 6th ed. MacMillan Publishing Co., New York. 609-646.

31. Rippe, B., R. C. Allison, J. C. Parker, and A. E. Taylor. 1984. Effects of histamine, serotonin, and norepinephrine on circulation of the dog. J. Appl. Physiol. 57:223-232.

32. Vehaskari, V. M., E. R. Root, F. G. Germuth, and A. M. Robson. 1982. Glomerular charge and urinary protein excretion: effects of systemic and intrarenal polycation infusion in the rat. Kidney Int. 22:127-135.

33. Bentzel, C. J., B. Hainau, S. Ho, S. W. Hui, A. Edelman, T. Anagnostopoulos, and E. L. Benedetti. 1980. Cytoplasmic regulation of tight-junction permeability: effect of plant cytokinins. Am. J. Physiol. 239:C75-C89.

34. Shasby, D. M., S. S. Shasby, J. M. Sullivan, and M. J. Peach. 1982. Role of endothelial cell cytoskeleton in control of endothelial permeability. Circ. Res. 51:657-661.

35. Wong, A. J., T. D. Pollard, and I. M. Herman. 1983. Actin filament stress fibers in vascular endothelial cells in vivo. Science (Wash. DC). 219:867-869.

36. Young, J. D., C. G. B. Peterson, P. Venge, and Z. A. Cohn. 1986. Mechanism of membrane damage mediated by human eosinophil cationic protein. Nature (Lond.). 321:613-615.

37. Della Bianca, V., M. Grzeskowiak, P. De Togni, M. Cassatella, and F. Rossi. 1985. Inhibition by verapamil of neutrophil responses to formylmethionylleucyphenylalanine and phorbol myristate acetate: mechanisms involving $\mathrm{Ca}^{+2}$ changes, cyclic AMP and protein kinase C. Biochim. Biophys. Acta. 845:223-236.

38. Foy, T., J. Morrion, K. L. Brigham, and T. R. Harris. 1979. Isoproterenol and aminophylline reduce lung capillary filtration during high permeability. J. Appl. Physiol. 46:146-151.

39. Gee, M. H., M. V. Tahamont, J. T. Flynn, J. W. Cox, R. H. Pullen, and N. A. Andreadis. 1987. Prostaglandin El prevents increased lung microvascular permeability during intravascular complement activation in sheep. Circ. Res. 61:420-428.

40. Conti, M. A., and R. S. Adelstein. 1980. Phosphorylation by cyclic adenosine 3:5-monophosphate-dependent protein kinase regulates myosin light chain kinase. Fed. Proc. 39:1569-1573.

41. Knight, D. E., and M. C. Scrutton. 1984. Cyclic nucleotides control a system which regulates Ca sensitivity of platelet secretion. Nature (Lond.). 309:613-616.

42. Boeynaems, J. M., N. Galand, and P. Ketelbant. 1985. Prostacyclin production by the deendothelialized rabbit aorta. J. Clin. Invest. 76:7-14.

43. Harlan, J. M., and K. S. Callahan. 1984. Role of hydrogen peroxide in the neutrophil-mediated release of prostacyclin from cultured endothelial cells. J. Clin. Invest. 74:442-448.

44. Gee, M. H., A. M. Havill, A. Premkumar, J. D. Washburner, R. Ottaviano, J. T. Flynn, and J. A. Spath, Jr. 1982. Lung lymph in the detection and assessment of lung microvascular injury. Ann. NY Acad. Sci. 384:381-393.

45. Brotherton, A. F. A. 1986. Induction of prostacyclin biosynthesis is closely associated with increased guanosine $3^{\prime}, 5^{\prime}$-cyclic monophosphate accumulation in cultured human endothelium. J. Clin. Invest. 78:1253-1260. 